\title{
OS LIMITES DA EXPRESSÃO. LINGUAGEM E REALIDADE EM SCHOPENHAUER
}

Jair Barboza*

SÍNTESE - Este texto procura mostrar como a concepção de linguagem de Schopenhauer implica uma delimitação para o poder da razão na teoria do conhecimento. Noutras palavras, a investigação da estrutura da linguagem jamais pode expressar o sentido do mundo.

PALAVRAS-CHAVE - Schopenhauer. Schelling.

Linguagem. Expressão. Verdade. Realidade.
ABSTRACT - This text aims to show how the language conception of Schopenhauer implies a delimitation for the power of reason in the theory of knowledge. In other words, the investigation of language's structure never can express the meaning of the world.

KEY WORDS - Schopenhauer. Schelling. Language. Expression. Truth. Reality.

I

Kant, na Crítica da Razão Pura, diz que o conhecimento do mundo começa quando dados do exterior nos são fornecidos nas formas puras a priori da sensibilidade, o espaço e o tempo. Sensibilidade que, para ele, é a receptividade do conhecimento. Depois de recebidos, os dados sensórios são pensados mediante doze categorias do entendimento, nele radicadas originariamente (unidade, pluralidade e totalidade; realidade, negação e limitação; inerência/subsistência, causalidade/dependência e comunidade; possibilidade/impossibilidade, existência/não existência e necessidade/contingência). Entendimento que também é chamado de espontaneidade do conhecimento. Daí a célebre frase da primeira crítica: "Conceitos sem intuições são vazios, intuições sem conceitos são cegas" [B 75].

O entendimento não intui, e a sensibilidade não pensa. Só do concurso de ambos surge o conhecimento. Mas esse conhecimento, alerta Kant, refere-se tãosomente às coisas tais quais elas nos aparecem, não como são em si mesmas. A coisa-em-si permanece um " $\mathrm{x}$ " desconhecido, mero objeto de pensamento, o limite da experiência possível, portanto o limite do discurso. Foi por ter tentado falar sobre ela, ou seja, sobre o incondicionado, que a metafísica enredou-se em ilusões, reduzindo-se a uma prática dogmática de pensamento. Com sua estética

Doutor. Professor da PUCPR (Pontifícia Universidade Católica do Paraná).

\begin{tabular}{|l|l|l|l|l|l|}
\hline VERITAS & Porto Alegre & v. 50 & n. 1 & Março 2005 & p. 127-135 \\
\hline
\end{tabular}


transcendental, ou teoria da sensibilidade, e sua analítica transcendental, ou teoria do entendimento, Kant coloca um fim às pretensões de conhecimento do incondicionado que marcara a metafísica anterior. Qualquer conhecimento tem de ser dado na nossa experiência. Entre nós e o em-si sempre haverá o entendimento e a sensibilidade, fazendo com que as coisas se dêem apenas na sua fenomenalidade.

Mas, embora o mundo da experiência seja formado de fenômenos, isso não significa de modo algum que aquilo que aparece é mera aparência fantasmagórica, destituída de realidade, porque senão, diz Kant, haveria uma aparência sem algo que aparecesse.

II

Ora, Schopenhauer, que se julgava o mais fiel intérprete de Kant, considerando a própria filosofia como um galho saído da dele, segue os passos básicos da epistemologia kantiana, porém realiza algumas mudanças de trajeto. Assim, se em Kant a sensibilidade e o entendimento estão nitidamente separados, do seu concurso nascendo qualquer discurso válido sobre o mundo, Schopenhauer, pelo contrário, vai uni-los. De fato, para o autor de O Mundo como Vontade e como Representação não faz sentido o entendimento ter doze categorias, pois todas as vezes que Kant dá um exemplo acurado delas sempre recorre à causalidade. Somente esta, em Schopenhauer, atua no entendimento. Por outro lado, o filósofo reaproveita as formas puras a priori da sensibilidade, o espaço e o tempo, contudo as realoca no entendimento, que agora passa a ter em si espaço, tempo e causalidade. Quer dizer, o entendimento é sensibilizado, ele em verdade intui o mundo. Schopenhauer denomina princípio de razão do devir esse modo de operação do entendimento, que procura para todos os dados exteriores ou interiores uma razão de ser, ou seja, fornece o fundamento dos objetos, dos fenômenos ou representações submetidas ao princípio de razão. Este, na sua acepção mais universal, reza: "nada é sem uma razão pela qual é". Se este princípio tudo explica, ele mesmo, entretanto, não é passível de explicação. Procurar uma prova para ele, sustenta o autor, denota ausência de clareza de consciência, pois quem exige uma prova para ele, isto é, seu fundamento, já o toma como verdadeiro, e assim cai no círculo que exige a prova do direito de exigir uma prova.

Assim, quando as sensações são fornecidas ao corpo, objeto imediato do conhecer, o entendimento (ou cérebro) as toma como um efeito e, pela causalidade, remonta temporalmente até a sua origem, posicionando-as no espaço como representações intuitivas, ou seja, objetos constituídos, imagens do mundo. O entendimento é uma espécie de artesão que constrói o mundo, a realidade sendo mais corretamente designada de efetividade, isto é, ela é um fazer-feito do sujeito que intui. Entendimento que os animais também possuem, como o mostrou "aquele elefante que, após ter atravessado várias pontes em sua jornada pela Europa, recusou-se certa vez a entrar numa, sobre a qual, como antes, viu o cortejo de homens e cavalos, porque ela lhe parecia muito levemente construída para o seu peso" (Die Welt I § 6). E todo esse trabalho do entendimento é inteiramente instin- 
tivo tanto no homem quanto no animal, como a secreção biliar ou a digestão; noutros termos, é inconsciente, não controlável pelo arbítrio.

Ora, tirante o entendimento como faculdade cognitiva, surgiu outra, que sobre a face da terra só o homem possui: a razão. Desponta aí "uma consciência completamente nova, que muito apropriadamente e com precisão infalível se denominou REFLEXÃO". Esta "é uma aparência refletida, algo derivado do conhecimento intuitivo e que, todavia, assumiu natureza e índole fundamentalmente diferentes, sem as formas do conhecimento intuitivo" (Die Welt I § 8). Nesse sentido, cabe à razão trabalhar o material do entendimento, ou seja, as intuições. A razão decanta essas intuições, as abstrai, fornecendo ao fim os conceitos ou representações de representações. A faculdade racional, portanto, na teoria do conhecimento de Schopenhauer, é secundária em relação ao entendimento. A razão só pode dar conceitos depois de ter recebido intuições. Daí o tropo óptico da reflexão ser perfeito para designar o seu trabalho: trata-se de simples reflexo, como num espelho, de material exterior. Tem-se na atividade de pensar, aparências refletidas, conteúdos depurados do material intuitivo. O intuicionismo de Schopenhauer, respeitando o pensamento de Hume, o leva a comparar a passagem da intuição para o conceitos da razão como se fosse a passagem da luz imediata e própria do sol para a luz refletida e emprestada da lua. Pensar é empalidecer o mundo. Hume já sentenciava que "o mais vivo pensamento é ainda inferior à mais embaçada das sensações"; todos os nossos pensamentos não passam de cópias das impressões dos sentidos externo e interno. O mundo da reflexão é um empalidecido mundo tomando de empréstimo por reflexo a algo a mais original. Por sua vez, Machados de Assis poderia resumir toda a discussão dizendo que nenhum romance de amor substitui o beijo da mulher enamorada.

Os animais com seu entendimento e ausência de razão vivem exclusivamente no presente; já o homem, com a razão, com o poder de pensar o passado e o futuro, vive simultaneamente em três dimensões temporais, muitas vezes para sua desvantagem, pois daí advêm sofrimentos imagináveis (futuro) e revividos (acontecimentos traumáticos do passado), que, juntados ao sofrimento presente, tornam no geral a vida humana mais sofredora que a dos seus irmãos animais. Eis por que muitas vezes olhamos invejosamente a suposta felicidade destes, imersos serenos no momento presente, como se este fora a eternidade sem tormentos.

Ora, é no contexto da razão que, com os conceitos, surge a linguagem como exclusividade humana na terra.

Enquanto o animal comunica sua sensação e disposição por gestos e sons, o homem os comunica junto com seus pensamentos aos outros mediante a linguagem, ou os oculta por ela. A linguagem, em verdade, é o primeiro e mais importante produto da razão, o seu instrumento necessário. Por isso, observa o filósofo, linguagem e razão, em grego, são indicadas com a mesma palavra: lógos.

Somente com a ajuda da linguagem a razão traz a bom termo as suas mais importantes realizações, como a ação concordante de muitos indivíduos, a cooperação planejada de milhares de pessoas, a civilização, o Estado, a ciência, a manutenção de experiências anteriores, a visão sumária de coisas comuns num único 
conceito, a comunicação da verdade, o pensamento e a ficção, mas também a propagação do erro, dos dogmas e das superstições. Ademais, se o animal conhece a morte tão-somente na morte, o homem, ao contrário, com a razão, aproximase de seu fim a cada hora com plena consciência, e isso torna a vida às vezes questionável, mesmo para quem ainda não conheceu, no todo mesmo da vida, o seu caráter de contínua aniquilação.

No Complemento 6 à sua obra principal, Schopenhauer observa que os conceitos da razão, embora não sejam idênticos às palavras, são uma representação abstrata cuja consciência clara e conservação, no entanto, liga-se necessariamente à palavra. Daí conceitos e palavras irem juntos, ou seja, a razão é indissociável do uso da linguagem. Devido ao fato de o tempo ser a forma arquetípica a priori de nossa mente, e a comunicação entre pessoas ser regida por ele, faz-se preciso letras (unidades lingüístico-temporais, pode-se assim dizer) e palavras, sons; fazse preciso elementos sensíveis para a audição, que fixem os conceitos, permitindo a estes serem transmitidos ao interlocutor. Nesse contexto, a fala, como objeto da experiência externa, manifestamente é, compara o autor, uma espécie de telégrafo bastante aperfeiçoado que comunica sinais arbitrários com grande rapidez e nuances. Quando alguém fala, não se traduz o seu discurso instantaneamente mas o sentido deste é intelectualizado, concebido e determinado de maneira precisa. É a razão que fala para a razão sem sair de seu domínio. O que ela comunica e recebe por palavras são conceitos abstratos.

A linguagem, por conseqüência, como qualquer outro fenômeno que se credita à faculdade racional, que diferencia o homem do animal, pode ser explicitada por esse único e simples elemento que a constitui: os conceitos veiculados por palavras, conceitos que são representações abstratas e universais, não individuais, não intuitivas, numa palavra, representações de representações.

Ora, como o material da razão é o conceito, e a linguagem o veicula, impõe-se agora averiguar qual o alcance do discurso, ou seja, da combinação dos conceitos que define o sentido da comunicação frasal em todos os níveis de expressão lingüística.

\section{III}

Na sua obra de juventude (originariamente sua tese doutoral) A Quádrupla Raiz do Princípio de Razão Suficiente (que antecede a O Mundo como Vontade e como Representação), que o próprio autor pressupõe como a leitura introdutória indispensável a sua obra principal, Schopenhauer desenvolve a base de sua interessante teoria da linguagem associada à forma lógica do juízo. Ali, a combinação de conceitos necessária à expressão recebe justamente o nome de juízo. Os elementos primários do juízo são exatamente os conceitos na acepção aqui exposta. Estes são ligados entre si para a linguagem tentar dizer significativamente o mundo. E essa tentativa de dizer o mundo se faz em diferentes níveis de ajuizamento, aos quais correspondem diferentes níveis de realidade. Isso implica diferentes perspectivas para a própria noção de verdade almejada pelo discurso. 
Na medida em que nos mantemos intuindo pelo entendimento, a verdade não é tema algum. O entendimento não se serve da linguagem. A sua verdade é de outra ordem, é a verdade ingênua do olhar, para o qual até mesmo as ilusões dos sentidos se apresentam como verdadeiras na sua imediatez, como no caso do bastão que se quebra quando mergulhado na água. Quando essa imediatez da intuição é suprimida e a consciência se ocupa com conceitos, por conseguinte refletimos com juízos formados, desfaz-se a ingenuidade. A razão destrói o ter-àmão o objeto, substituindo no intelecto o trabalho do entendimento. Com isso, é aceitável falar agora sobre verdade e erro, ou seja, indagar sobre a validade dos juízos. Nesse âmbito surge, no pensamento de Schopenhauer, os, por assim dizer, níveis de verdade, de discurso, equivalentes a níveis de realidade. Nesse âmbito surge propriamente o saber, que significa ter determinados juízos em poder do próprio espírito para reprodução ulterior. Ora, o saber almeja a verdade. Cabe pois perguntar neste momento que é, na sua acepção estrita, a verdade? O filósofo responde: é a relação de um juízo com algo exterior a ele - seu fundamento suficiente. Os fundamentos nos quais os juízos ditos verdadeiros se baseiam são, por sua vez, distribuídos em quatro classes, segundo as quais se tem quatro tipos de verdade, quatro níveis lingüísticos de expressão da realidade.

1) VERDADE LÓGICA. Um juízo tem por fundamento um outro juízo. Trata-se de uma verdade formal. Toda silogística não passa de regras para o emprego do princípio de razão nos juízos, portanto é o cânone da verdade lógica. Fundamentadas por outros juízos são também as verdades estabelecidas a partir das assim chamadas quatro leis do pensamento: por exemplo: a) o juízo "um triângulo é um espaço encerrado por três linhas" é uma verdade que tem como último fundamento o princípio de identidade, isto é, o pensamento expresso a partir deste; b) o juízo "nenhum corpo é sem extensão" tem como último fundamento o princípio de contradição; c) o juízo "todo juízo é ou verdadeiro ou não verdadeiro" tem como último fundamento o princípio do terceiro excluído; d) o juízo "ninguém pode tomar algo como verdadeiro sem saber por que" tem como último fundamento o próprio princípio de razão de conhecer. Com isso se pode afirmar que toda verdade lógica é extrínseca, é a relação de um juízo com algo exterior a ele, de modo que verdade intrínseca, que só se apoiaria nas leis do pensamento e não em outros juízos, é uma contradição nos termos.

2) VERDADE EMPÍRICA. Nessa classe de verdades um juízo tem por fundamento uma intuição empírica. Trata-se de uma verdade material, baseada diretamente na experiência. Um juízo possuir verdade material significa que os seus conceitos estão ligados, separados, limitados entre si de tal maneira como estão dispostas as intuições empíricas que o fundamentam. Conhecer essa concordância entre a estrutura do discurso e a estrutura da realidade é tarefa precípua da faculdade de juízo propriamente dita, intermediária entre as faculdades de intuição (entendimento) e de abstração (razão).

3) VERDADE TRANSCENDENTAL. As condições formais de toda intuição, o tempo, o espaço e a causalidade, radicadas originariamente no entendimento, podem ser o fundamento de um juízo, que então é sintético a priori. Trata-se aqui 
dos conhecimentos matemáticos. Exemplos de tais juízos são, no que se refere ao espaço, "duas linhas retas não encerram espaço algum"; no que se refere ao tempo: "3 x $7=21$ "; no que se refere à causalidade: "a matéria não nasce nem perece".

4) VERDADE METALÓGICA. As condições formais de todo o pensamento, encontradas a priori na razão, podem ser o fundamento de um juízo, cuja verdade é denominada metalógica. Os juízos metalógicos, segundo o filósofo, são apenas em número de quatro: a) "um sujeito é igual à soma de seus predicados ou, a = a"; b) "um predicado não pode ao mesmo tempo ser atribuído e retirado ao sujeito" ou " $\mathrm{a}=-\mathrm{a}=0$ "; $\mathrm{c}$ ) "de dois predicados opostos e contraditórias um tem de convir ao sujeito"; d) "a verdade é a relação de um juízo com algo exterior a ele, que é o seu fundamento suficiente". É a "auto-investigação" da razão que conduz a reconhecer que todos esses juízos são a expressão das condições do pensamento em geral. Curiosamente, para Schopenhauer, há uma grande semelhança não entre as verdades lógicas e meta-lógicas, mas sim entre estas e as transcendentais, porque ambas se baseiam em condições formais do conhecer — num caso as condições do pensamento (verdades metalógicas), no outro as condições da intuição (verdades transcendentais).

Assim, não há verdade (teoria do juízo) intrínseca; a verdade é por natureza extrínseca. No caso das intuição empírica, da representação submetida ao princípio de razão do devir, a sua verdade pode ser dita intrínseca, mas meramente no sentido de ser a verdade ingênua do olhar, e que, mesmo em se tratando de um engano dos sentidos, como no exemplo do bastão quebrado ao ser mergulhado na água, jamais pode ser corrigida pela razão, precisamente porque não se trata aí de verdade extrínseca, ou seja, da relação de um juízo com um fundamento exterior a ele.

O que se conclui, pois, desse quádruplo recorte da linguagem é precisamente a disposição quádrupla do discurso, com formas lógicas específicas do juízo, correspondente a quatro dimensões de realidade. A filosofia doravante demarca níveis de discurso. São indicações de regras de jogo. Tem-se um perspectivismo da noção de verdade, de tal maneira que não faz sentido, a partir da verdade lógica, querer corrigir a verdade empírica, e vice-versa; bem como não faz sentido, a partir da verdade transcendental, querer definir as verdade meta-lógica, e viceversa; e assim por diante. Daí também se extrai uma crítica à linguagem demasiado abstrata em filosofia, logo, uma crítica estilística aos sistemas filosóficos abstrusos. Explique-se: no domínio das verdades empíricas, no qual se localiza, para a filosofia, a referência exterior de seu discurso, os conceitos têm de ser remetidos a intuições, e de um modo tal que a estrutura da frase corresponda à ordenação fenomênica do mundo. A intuição tem de controlar o discurso. Pois, como observa o mencionado Complemento 6 de $O$ mundo..., todo processo de abstração consiste numa eliminação. Quanto mais se avança no pensamento abstrato, mais se perde. Os conceitos mais universais da filosofia, nesse sentido, são os que menos dizem, como os conceitos de SER, ESSEENCIA, COISA, DEVIR, INFINITO, FINITO, SUBSTÂNCIA. Segue-se que as filosofias a se servirem insistentemente de tais termos são as 
mais vazias. Sobretudo no hegelianismo Schopenhauer identifica semelhante defeito. Cabe endereçar a elas, pois, a crítica estilística mais cortante.

Com isso, a expressão lingüística tem um limite. Este limite, em Schopenhauer, é atingido com a chamada verdade filosófica por excelência. Aqui não se trata, como nas outras verdades, da relação de uma representação abstrata com outra representação (verdade lógica) ou com a forma necessária do representar intuitivo (verdade transcendental) ou do representar abstrato (verdade metalógica), nem a referência de conceitos a intuições empíricas (verdade empírica). Não se trata, ainda, de indicar uma Idéia intuída esteticamente pela faculdade genial, como no caso da poesia e da contemplação estética em geral. Trata-se, ao contrário, da referência de um juízo à relação de uma representação intuitiva, o corpo, com algo toto genere diferente da representação, a vontade. A expressão dessa verdade pode ser dita de diversos modos: "meu corpo e minha vontade são uma coisa só"; "a vontade é o conhecimento a priori do corpo"; "o corpo é o conhecimento a posteriori da vontade"; "meu corpo é a objetidade da vontade"; "se se abstrai o fato de que o corpo é representação, ele é simplesmente a minha pura vontade".

Quer dizer, Schopenhauer aponta pela verdade filosófica os limites da expressão, já que aqui o conhecimento conceitual é substituído pelo conhecimento baseado no sentimento do corpo. E este sentimento é traduzido pela palavra do enigma: vontade. Esta, depois de identificada como o núcleo do próprio corpo do investigador, a sua coisa-em-si (o que qualquer um pode averiguar pelo exame intelectivo da auto-consciência) é estendida, via conclusão analógica, ao restante do mundo. O corpo de cada um é idêntico aos demais corpos, no sentido de todos estarem submetidos à causalidade e situados no espaço e no tempo. Neste aspecto não há diferença entre os corpos. Ora, ao se observar o próprio corpo, isso implica observar a causalidade vista de dentro, pois quando agimos guiados por algum motivo estamos agindo por causalidade, assim como um corpo que cai o faz devido à causalidade no sentido estrito do termo, ou uma planta quando se excita o faz devido a essa forma de causalidade que é a excitação. Logo, a causalidade em sentido estrito, a excitação e a motivação não se diferenciam em natureza, mas apenas em qualidade. Portanto, ao observar o íntimo do meu próprio corpo, ao observar os seus móbiles em ações executadas, reconheço sempre a vontade por trás deles. Daí poder extrair a conclusão válida universalmente de que a vontade é a essência não só minha, mas do mundo inteiro.

Eis aí, para o autor de O Mundo como Vontade e como Representação, a verdade metafísica por excelência, não atingida pela razão, pelo discurso, mas pelo sentimento do corpo. É o limite da expressão.

Com isso, a linguagem não explica a essência do mundo. A linguagem, e aqui se inclui também a científica e a lógica, expressa o mundo, COMo ele nos aparece, mas não o oû́ dele. O que remete Este quê, como tal, é exterior ao como do mundo, refletido pelo discurso. É o quê metafísico, além do físico, e, apesar de indizível, inefável, pode no entanto ser sentido e apontado exteriormente no domínio da ética e da estética, ou seja, no domínio do místico, não submetido ao princípio de razão, não cabível na linguagem lógico-científica nem na filosófica que se 
orienta por esses parâmetros. Nisso o filósofo segue em parte o caminho de Kant, para quem a coisa-em-si, por trás do fenômeno, enquanto " $\mathrm{x}$ " desconhecido, é indizível, embora dê sentido ao dizível dos fenômenos. A linguagem, em Kant, cabe apenas ao fenômeno e aí encontra o limite de sua significação.

Nota-se, assim, o objetivo de Schopenhauer com a sua teoria da linguagem e os níveis de realidade que ela expressa. No fundo, ele prepara o terreno para revolucionar a tradição filosófica ocidental, a saber, o princípio do mundo não algo racional, inteligível, mas antes algo volitivo, cego e sem-fundamento. A expressão conceitual jamais a alcança. O real, portanto, furtar-se ao princípio de razão. Numa palavra, o fundo último das coisas é a-lógico, irracional. Logo, conclua o leitor, nenhuma teoria do juízo e da linguagem pode dizer algo de extremamente significativo sobre a natureza das coisas.

O despotenciamento da razão como conseqüência necessária da teoria da linguagem schopenhauereana é tanto mais significativo se se leva em conta o momento em que essa filosofia surge. Schelling, que abre caminho para Hegel, diz que a razão é capaz de uma intuição intelectual que dá acesso ao absoluto. Nós não temos essa razão, mas é ela, pelo contrário, enquanto universal e eterna, que nos tem. O conceito de razão em Schelling ultrapassa a noção de uma mera faculdade de abstração do indivíduo, formadora de conceitos e destinada à reflexão a partir da finitude, como o será em Schopenhauer, e é considerada como uma potência universal, a tudo organizando, do menor ao maior. Para se pensar nela é preciso abstrair até mesmo o indivíduo que pensa. Schelling diz que, para aquele que é capaz de uma tal abstração, a razão "cessa imediatamente de ser algo subjetivo, como ela é representada pela maioria das pessoas". Ela se torna "o verdadeiro em-si", situado num ponto de indiferença entre subjetivo e objetivo. A filosofia será levada à conclusão de que "exteriormente à razão não há nada e nela está tudo." O ponto de vista da filosofia é o do conhecimento das coisas como elas são em si na razão. A filosofia só existe do "ponto de vista do absoluto" e "a razão é o absoluto". Fichte, na exposição de sua doutrina-da-ciência, também postula uma razão supra-individual que, em relação à individualidade, é "o único em-si", sendo a personalidade apenas meio para exprimi-la. Somente a razão é "eterna", enquanto a individualidade tem de morrer aos poucos.

O que Schopenhauer responde claramente a essa tradição é que a razão obtém a verdade apenas da finitude, e somente a esta ela expressa, ou seja, às aparências temporais. Ela lida tão-somente com aquilo que é condicionado, relativo, ou seja, com aquilo que já anteriormente foi dado pela experiência. O princípio de razão não nos leva para além da experiência e nem decifra o enigma desta. Seguindo a lição de Hume, em Schopenhauer o entendimento e a experiência por ele apreendida é o limite intransponível para a discursividade da razão especulativa. Por conseqüência, o mais detalhado estudo sobre a razão e a estrutura da linguagem jamais revelará o que é o mundo. A filosofia não se confunde de maneira alguma com a filosofia da linguagem, já que o mundo, no seu íntimo, é absurdo e somos assim impotentes com a reflexão para atribuir-lhe algum sentido lógico. O fio condutor do princípio de razão nunca alcança um fim último, nem pode forne- 
cer uma explicação completa e suficiente do mundo, porque jamais toca a essência mais íntima dele, jamais vai além da representação, antes, basicamente, somente conhece a relação de uma representação com outra representação, e assim, não vai além desta.

\section{Referências}

SCHELLING, F. W. J. "Darstellung meines Systems der Philosophie". - "Erster Entwurf eines Systems der Naturphilosophie" In: Sämtliche Werke, vols. III e IV. Edição de K.F.A. Schelling. Sttutgart: Cotta, 1856-61.

SCHOPENHAUER, A. "Die Welt als Wille und Vorstelling I e II". - "Über die vierfache Wurzel des Satzes vom zurreichenden Grunde". In: Edição "letzter Hand" de Ludger Lütkehaus, vols. I, II e III. Zürich: Haffmans, 1988, 